\title{
Sindicalismo docente renascido
}

Teacher unionism reborn

Lois Weiner*

New Jersey City University

Resumo $\quad \mathrm{O}$ texto discute como os sindicatos docentes têm sido visados e atacados, porque constituem o mais significativo obstáculo, em todo o mundo, para a implementação do projeto de reforma escolar que vem sendo imposto há quarenta anos. Os sindicatos docentes sofrem um espetacular ataque, ao mesmo tempo em que formas de resistência em diversas partes do mundo mostram-se poderosas e persistentes. $\mathrm{O}$ artigo apresenta, de forma geral, as políticas das duas principais entidades sindicais nos EUA - NEA e AFT - e demonstra o aumento de movimentos de resistência emergente que questionam e tentam modificar as lutas nesses sindicatos. Por fim, a autora advoga a necessidade de que essa militância sindical emergente ocupe os sindicatos para dar outro sentido à luta política em defesa dos professores e da educação pública.

PALAVRAS-CHAVE: Sindicalismo Docente, Resistência, Docentes.

Abstract This paper discusses how teachers unions have been singled out for attack because throughout the world they are the most significant barriers to this project of education reform that has been implemented in the last four decades. Teachers unions globally have experienced an astoundingly well-orchestrated, well-financed attack, and resistance elsewhere in the world has been forceful and persistent. This article presents the policies of the major teacher unions in the USA - NEA and AFT - demonstrating the efforts of an emergent resistance of activists who have questioned political actions of both national unions in the teachers battles. At last, the author defends that emergent group of activists must occupy unions in order to change their way of fighting in defense of teachers and public education.

KEYWORDS: Teacher Unionism, Resistance, Teachers. 


\section{Sindicalismo docente renascido}

Nos últimos cinco anos, temos testemunhado uma demonização, dos sindicatos docentes, que busca alcançar o seguinte objetivo: a destruição do mais estável e potencialmente poderoso defensor da educação pública de massas. A existência contínua do sindicalismo docente está ameaçada — se o que definimos como "existência" são organizações que possuem a capacidade legal para barganhar benefícios econômicos significativos, e defender os direitos da categoria para exercer o juízo profissional sobre o que ensinar e como ensinar.

Como expus em outro trabalho, as elites financeiras e políticas iniciaram este projeto há quarenta anos, quando impuseram uma reforma escolar na América Latina, África e Ásia, como um "toma lá dá cá" para as ajudas econômicas. Mesmo que especificidades dessa engenharia social global se apresentem de um país para outro, as reformas possuem uma mesma marca: o financiamento educacional sofre cortes e os sistemas escolares são sucateados para que a privatização seja promovida sob a bandeira da "escolha"; docentes e currículo são controlados pela vinculação com os resultados dos testes padronizados e a eliminação da estabilidade; testes padronizados medem o que é ensinado para a maioria dos estudantes, reduzindo os conteúdos para o básico em matemática, leitura e escrita. Os sindicatos docentes têm sido visados e atacados porque constituem o mais significativo obstáculo, em todo o mundo, para a implementação deste projeto.

A retórica de resultados escolares equânimes para grupos historicamente alijados de um acesso a uma educação adequada deixa a qualidade da educação de lado, e mascara o objetivo verdadeiro dos últimos vinte anos de reforma, criando uma força de trabalho dócil que recebe, não mais do que uma educação de oito anos, necessária para competir com outros trabalhadores por empregos que podem, facilmente, se mover de uma cidade, de um estado ou de um país. Os documentos do Banco Mundial baseiam-se em teses dificilmente articuladas com os países: dinheiro para educar trabalhadores além do nível do mínimo necessário é um desperdício dos escassos financiamentos públicos; para trabalhadores minimamente educados são requeridos professores minimamente educados, cujo desempenho pode ser monitorado por testes padronizados. O recente relatório do Banco Mundial "Making Schools Work" leva este argumento (e a política) mais longe, insistindo que "contratar professores" que trabalhem por um quarto do que empregados do serviço civil recebem, sem benefícios, sem proteção de emprego e sem direitos, produz bons resultados.

O ataque tem sido recarregado por fundações de orientação direitista e avançado, de forma similar, entre Democratas e Republicanos. A mídia corporativa, incluindo as tradicionalmente liberais, como Hollywood, The New Yorker e The New York Times, fornece subsídios para as TVs, rádios, e a imprensa escrita com falsas premissas sobre educação e sua relação com a economia é o papel dos sindicatos docentes no bloqueio das mudanças necessárias. O governo Obama retira, diretamente, da cartilha de reformas educacionais das fundações de direita, o discurso educacional como panaceia para o desemprego e a pobreza. Quando o 
Ministro da Educação Arne Duncan declara que a educação é o "único caminho verdadeiro para superar a pobreza", ele demonstra a intenção da administração em desviar a atenção do desemprego, dos problemas de saúde pública, da fome infantil e dos sem-teto. A melhoria da escola suplanta todas as reformas sociais e econômicas que têm sido utilizadas, historicamente, para reduzir a pobreza. Defensores da educação pública frequentemente respondem a essas inflamadas defesas da educação com protestos de que as escolas nada podem fazer para alterar o destino das crianças pobres. Infelizmente, essas respostas servem para aumentar a percepção do público de que as pessoas da escola - professores - recusam-se a assumir responsabilidade pelo que ocorre sob o seu cuidado. A resposta mais precisa e politicamente efetiva é que as escolas podem fazer mais e melhor se tiverem professores mais bem preparados e com melhor apoio para um trabalho em escolas com melhores condições de recursos materiais, e que, mesmo com essas condições, as escolas são reféns de forças poderosas que reduzem o êxito escolar - fatores que estão fora do seu controle. Esta defesa mais diferenciada da educação pública e dos professores nos ajuda a desestabilizar um dos principais problemas que enfrentamos, ao defender a educação pública, a exploração que o neoliberalismo faz das históricas desigualdades em educação. Isso é particularmente verdadeiro nos Estados Unidos, onde a retórica do movimento dos direitos civis tem sido totalmente sequestrada para a defesa das escolas charter e da melhoria da "qualidade docente" pela eliminação das carreiras e estabilidade. Mesmo a publicação The Nation tem aderido à reificação do desempenho docente individual como condição sine qua non para a melhoria da escola.

Os sindicatos docentes sofrem um espetacular, bem orquestrado e financiado ataque, ao mesmo tempo em que formas de resistência em diversas partes do mundo mostram-se poderosas e persistentes, os sindicatos de professores nos Estados Unidos têm sido alvos fáceis. A maioria dos professores pertencem a uma seção local filiada ao NEA (National Education Association) ou ao AFT (American Federation of Teachers). Ambos, NEA e AFT, são sindicatos nacionais com organizações em âmbito estadual. Em geral, professores das cidades maiores estão no AFT, o qual é membro do AFL-CIO. O NEA funciona como um sindicato e colabora com trabalhos sobre legislação e na política, mas não está na AFL-CIO. No NEA, as organizações estaduais são o seu mais poderoso componente. Para o AFT, o afiliado local é chave. Os dirigentes e a burocracia controlam o NEA, os afiliados locais o AFT. Na maior parte dos sistemas escolares o aparato sindical está intacto, mas as organizações estão bloqueadas, enfraquecidas pelo envolvimento com os "negócios (tarefas) sindicais" ou "modelos de serviços" que caracterizam a maioria dos sindicatos nos EUA. A sinergia do ethos hierárquico do sindicalismo de business e a base legal que dá direito aos sindicatos negociarem em nome dos professores, como representação exclusiva de agente negociador, o direito de recolher "taxas" (pagamento para o sindicato do que é geralmente equivalente aos valores para cobrir despesas que o sindicato realiza com a negociação e para garantir os contratos), e cobranças de desconto sindical (dedução automática de taxas no contra-cheque dos filiados) têm encorajado uma visão muito burocrática para estabelecimento do contrato, uma passividade dos filiados, e uma erosão da 
representação sindical nas escolas - representante escolar. Os representantes sindicais locais e os militantes têm sido, muitas vezes, ingênuos em responder aos bombardeios ácidos de críticas, e os sindicatos nacionais ajudam muito pouco. Eles não estão dispostos a "desestabilizar o barco", desejando acima de tudo manterem-se politicamente alinhados com Obama, um presidente que tem sistematicamente defendido uma agenda anti-professores, anti-sindical e antieducação pública. Outro fator é, obviamente, o poder pessoal e o privilégio que os representantes sindicais e suas equipes gozam como resultado de seu confortável relacionamento com as poderosas elites.

No início da educação pública de massas, os sindicatos docentes, assim como a maioria das organizações do trabalho, ficavam cegos ao racismo e ao sentimento anti-imigrantes. Os Sindicatos docentes demonstram dificuldade em reconhecer essa história, o que tem Ihe facilitado a vida como grupo de interesse especial - inacreditavelmente, por bilionários que saquearam os recursos da nação -, mais interessados em proteger seus empregos do que ajudar crianças pobres a ter sucesso na escola. Muitos pais e cidadãos, mesmo alguns professores, têm sido persuadidos de que estabilidade e carreira protegem "madeira podre", não percebendo que, quando a carreira e a estabilidade são perdidas, o mesmo acontece nas salas de aula. A má vontade dos sindicatos para reconhecer a função da escolarização, no passado e no presente, de reprodução da desigualdade social, sua relutância em trabalhar em parceria com militantes para assumir a luta contra o racismo, o sexismo, a militarização, e contra o preconceito anti-imigrante tem enfraquecido sua credibilidade com grupos que deveriam ter os sindicatos docentes como fortes aliados.

Esse problema pode ser exemplificado com a defesa dos sindicatos de professores feita por Diane Ravitch . Diferentemente de Chester Finn, um exaliado que se gaba por seu desejo de destruir a educação pública, Ravitch entende que, uma vez que a educação pública seja destruída, como Humpty Dumpty, não será possível um restabelecimento coeso da sociedade - pois quando a educação vai bem pode se transformar em uma poderosa força para a democracia. Outra explicação para a reviravolta de Ravitch sobre as reformas neoliberais que ela defendeu, quando participou do Governo Bush, é de que ela é uma intelectual e, ao contrário de seus ex-aliados neoconservadores, está autenticamente interessada na educação. Ela está, certamente, horrorizada com o anti-intelectualismo muito presente nos esforços bem sucedidos do neoliberalismo em atribuir uma vocação para a educação. Muito do que ela escreve é eloquente, apaixonado e preciso. Muito diferente do que os desorientados burocratas que dirigem os sindicatos, Ravitch entende que a luta precisa ser feita e está disposta a isso. Ravitch criticou o controle sobre as escolas de Nova York, proposto pela prefeitura como antidemocrático, enquanto o presidente do sindicato, que representa os professores, apoiou as medidas. Ravitch tem se colocado contra o vínculo do pagamento de salários aos resultados dos testes, enquanto os sindicatos nacionais têm cedido neste ponto, e mostrado aos sindicalistas burocratas como poderiam, se quisessem, defender o sindicato e a educação pública de forma mais efetiva. Ela é uma espécie 
de sósia de Albert Shanker, ele ainda atua como presidente de sindicato em vez de administrador do trabalho.

Contudo, como foi o caso de Shanker e continua verdadeiro para os dirigentes da NEA e AFT, a defesa de Ravitch do sindicalismo docente e da educação pública está circunscrita a um compromisso ideológico com a defesa do capitalismo norte-americano a qualquer custo. Como Ravitch não pode ou não reconhecerá o que está errado com a educação pública e a sociedade norteamericana, ela não pode conceber uma alternativa para as reformas neoliberais. Está sutilmente embutido, na sua defesa da educação pública, a ideia de que não havia crise na educação pública antes da imposição das reformas neoliberais. Mas havia. Os historiadores de esquerda, que ela tentou destruir, nos anos de 1960 e 1970, com sua defesa do status quo, sabiam disso. As escolas reproduziam - e reproduzem - a desigualdade social. Em um recente ensaio, na New York Review of Books (September 29, 2011), Ravitch reduz a atual desigualdade entre brancos e minorias a mais uma série de crises estrondosas dentre as crises que as escolas nos EUA têm sofrido desde sua criação. Argumenta ser "uma questão de pobreza", o que é obviamente, assim como o racismo, que ela não menciona. Assim como outras formas de discriminação que ela ignora. Em outro texto, Ravitch afirma seu desejo de que a educação pública seja a mesma que ela teve no ensino médio, em Houston, no Texas. (Na história da educação pública dos EUA da PBS Public Broadcasting Service, Ravitch afetuosamente relembra seus dias como líder de torcida - cheerleader - no ensino médio.) Mas, como muitos pais negros e hispânicos vão lutar por um retorno ao status quo que impedia suas crianças de frequentar as escolas que serviam aos brancos?

\section{Uma resistência emergente}

As maiores cidades do país foram a sede do surgimento do sindicalismo docente e de seu ressurgimento nos anos de 1960. As articulações da oposição atual emergem novamente nas cidades onde as condições foram deterioradas em um nível inimaginável, mesmo há uma década atrás. Escolas Charter, conforme seus proponentes livremente admitem, são uma das principais armas para transformar os sistemas escolares livres da influência sindical. Uma escola charter é essencialmente seu próprio distrito escolar, livre das regulações distritais - e do envolvimento sindical. Na maioria das cidades grandes, os sindicatos docentes optaram pela transferência, pelo critério da antiguidade, quando a primeira onda de fechamento de escolas teve início. Agora, quando escolas são fechadas por causa de resultados ruins nos testes e substituídas por escolas charter, professores experientes são frequentemente jogados em depósitos de "professores à disposição", eles devem competir por empregos com novos contratados, que ganham a metade do salário. A remuneração dos professores agora sai do orçamento da escola, então, muitos diretores, especialmente aqueles com pouca ou nenhuma experiência de ensino, preferem empregar dois novos professores pelo preço de um mais experiente. Um fato pouco divulgado pelos sindicatos é de docentes mais velhos e de minorias enfrentam intenso racismo quando fazem entrevistas para obter emprego, 
especialmente com jovens diretores brancos. Leitores familiarizados com a história do trabalho enxergarão os espantosos e desanimadores paralelos com o "moldarse" às docas e campos, antes do sindicalismo, obter escritórios de contratação e formas de proteção para trabalhadores velhos.

Embora a estabilidade tenha sido considerada irrelevante no ensino básico, é mais importante hoje do que fora anteriormente. Como o pagamento dos diretores está crescentemente vinculado à melhoria dos resultados nos testes, e as armadilhas entre o pagamento dos professores e o resultado dos estudantes nos testes estão amarrados, os professores, que querem dar a seus estudantes uma dieta mais rica do que a pobre preparação para os testes, estão enfrentando a possibilidade de perderem seus trabalhos se continuarem com seus princípios morais e profissionais. Cada vez mais alarmante é o uso pelas escolas da propaganda corporativa, obtida por meio de vendedores aparentemente honestos, como ocorreu com Scholastic Books, que promovia um currículo escrito para a 4a. série produzido pela indústria do carvão e com a sua própria perspectiva. Mesmo, onde ainda existe com base em leis estaduais, a estabilidade docente tem sido muito enfraquecida porque os administradores podem, facilmente, atribuir aos docentes taxas espúrias devido à enfraquecida aplicação dos procedimentos de avaliação. Em muitas escolas da cidade, diretores podem e trabalham sem qualquer questionamento ao seu poder, exceto aqueles que podem ser exercidos por supervisores externos cuja preocupação são, somente, os resultados nos testes. Mais e mais se ouve, de professores que assimilaram a propaganda anti-sindicato, tão prevalente na mídia, que estão tão sobrecarregados e desmoralizados para fazer alguma coisa além do que são orientados a fazer, ou que estão tão receosos de retrucar para emitir uma voz contrária de opinião. A presença do sindicato tem sido tão corroída e sua credibilidade tão danificada que "mudar o sindicato", em muitos distritos, provavelmente significa começar do zero.

Ao mesmo tempo, alguns professores politizam-se no seu dia a dia, pelos injustos ataques políticos às suas habilidades, ao seu caráter, à sua autoridade profissional e ao seu bem-estar econômico. Ademais, muitas vezes eles se apegam ao "modelo de serviço" do sindicalismo e esperam que "o sindicato", de algum modo, magicamente, intervenha. A ideia de que eles SÃO o sindicato está, aos poucos, se infiltrando, e, de forma crescente, uma nova geração militante do movimento docente está emergindo. A renovação sindical está tomando formas variadas, mas, a mais importante, do ponto de vista estratégico, está ocorrendo em muitas cidades país afora. Nem todas as grandes cidades estão vivenciando o tipo de mudança que é necessária. Por exemplo, em Washington D.C., uma prolongada ação jurídica finalmente bem sucedida, encaminhada por um dirigente sindical candidato à presidência, ajudou muito pouco na mobilização dos professores e da comunidade. Por outro lado, no sindicato docente de Chicago, uma liderança vibrante, majoritariamente nova para a diretoria do sindicato, tem tido um compromisso para mobilizar os filiados, rejeitando explicitamente o sindicalismo de negócios. Em Milwaukee, um militante no campo da educação por longo período, Bob Peterson, um dos fundadores do jornal Rethinking Schools, preside, neste momento, o sindicato docente de Milwaukee. Professores de esquerda que 
antes, rejeitavam o sindicato, agora, o aceitam como necessários para proteger os direitos econômicos do professorado e, como Peterson, veem o sindicato como capaz de lutar por um "tripé" de preocupações: "sindicalismo pão com manteiga... sindicalismo profissional... e sindicalismo justiça social". Peterson assinala a necessidade de alianças mútuas verdadeiras, em que se construam relações fortes com pais e grupos comunitários "não somente para se assegurar um apoio à educação pública, mas para que nós, como um sindicato, estejamos também envolvidos em melhorar a comunidade."

Embora Rethinking Schools e outros usem o termo sindicato "justiça social", eu penso que a ideia de um sindicato "movimento social" seja mais útil, porque indica a necessidade de transformar os sindicatos internamente, especialmente a necessidade de uma democracia sindical. Democracia sindical é um tema espinhoso para a esquerda, especialmente para quem assume a liderança de organizações moribundas. Sindicalismo "Justiça Social" indica as posições que o sindicato toma em relação aos vários temas políticos, sociais e econômicos. Um desafio para a esquerda, que assume diretorias sem uma base mobilizada de apoio, é que a democracia sindical se transforma em um impedimento para a ação sindical de um programa de "justiça social". De outro lado, "movimento social" visa à necessidade de empoderar os filiados do sindicato, construindo uma entidade de baixo para cima, transformando o próprio sindicato em um movimento social. Um sindicato de movimento social, não só reforça as demandas por justiça social na educação e na sociedade, trabalhando com os movimentos sociais para atingir esses objetivos, mas também existe como um movimento social em si, que luta tanto quanto pode contra as limitações de ser uma organização de filiados - com a responsabilidade de proteger seus filiados.

O CTU, provavelmente, é o mais importante teste de base para o sindicalismo movimento social. O sindicato está sendo dirigido por militantes do CORE (Caucus of Rank-and-File Educators). Utilizando as novíssimas mídias sociais e o tradicional cara a cara para reuniões e organização, o grupo CORE derrotou a mais velha liderança fiel à seção nacional da AFT. Com apenas um segundo para recuperar o fôlego, os novos líderes do CTU sofreram ataques ferozes do estado e da municipalidade no que se refere ao contrato e às pensões dos professores. Ainda adquirindo experiência política, a liderança inexperiente cometeu erros naturais e desastrosos, por exemplo, confiou aos diretores da seção estadual do sindicato, por considerar que fossem mais preparados para as decisões de políticas e permitiu que o presidente estadual participasse de reuniões com o alto escalão do estado em seu lugar. A liderança do CTU enfrenta uma dramática falange de opositores, num leque que vai desde o prefeito Rahm Emmanuel, que exibe o prestígio e o apoio que possui na Casa Branca e de poderosos "amigos do trabalho" do Partido Democrata, alcançando políticos estaduais Democratas e Republicanos, prontos para destruir todos os sindicatos de funcionários públicos, mais especialmente, aqueles que representam os professores. Ademais, os líderes do CTU tem que obter recursos do sindicato nacional e estadual necessários e, simultaneamente, fazer tudo o que for preciso para expulsar os dirigentes que 
impedem os objetivos do movimento. Na minha opinião, os militantes do CORE são uma inspiração heróica e sábia.

Assim como em outras cidades, os professores de Los Angeles enfrentam uma brutal ação do prefeito contra o sindicato docente. Porém, o que diferencia o prefeito de Los Angeles, Antonio Villaraigosa, é que ele se aproveita de suas posições como um ex-membro da equipe do sindicato, United Teachers of Los Angeles (UTLA), e pela sua relação próxima com dois dirigentes do alto escalão do UTLA - esquerdistas conhecidos - que o ajudaram a se tornar um expoente do trabalhismo e, após, prefeito. UTLA foi o primeiro sindicato de professores de uma grande cidade que, por uma assembleia de reforma, conseguiu varrer a velha guarda da entidade. Contudo, somente uma pequena fração dos filiados votou na eleição (assim como na eleição mais recente). A nova direção está na indesejável posição de ter que responder aos terríveis ataques e, ao mesmo tempo, administrar a burocracia do sindicato, sem poder contra o apoio massivo da base. Infelizmente, a direção que tomou a entidade em uma coalizão que não permite uma discussão de responsabilidades entre as facções, mantendo muitas das práticas burocráticas da gestão anterior. A desastrosa decisão da liderança em apoiar o controle da prefeitura - porque o prefeito era parceiro - foi uma questão de ênfase nas relações políticas de poder ou de foco no papel burocrático do sindicato. Nas eleições mais recentes, um antigo militante concorreu como candidato independente, mas, alinhado com a bancada mais conservadora, venceu a presidência. Ao mesmo tempo, uma articulação progressista, PEAC, obteve maioria dos assentos na diretoria do sindicato. O que precisa ser feito agora - e rapidamente - é com que os líderes e militantes coloquem os recursos humanos e financeiros para reviver o sindicato nas escolas. Provavelmente, em um terço das escolas campi, como são chamadas, há problemas de funcionamento. Este trabalho reconhecidamente penoso de educar membros do sindicato que pensam que são os "donos" da entidade, para ajudá-los a se organizarem, é inevitável. Um ponto positivo da vitória dos progressistas é que a Comissão de Recursos Humanos se engajou no trabalho com sindicatos canadense e mexicano, sob a égide da Coalizão Trinacional em Defesa da Educação Pública.

De todos os sindicatos das maiores cidades nos EUA, à primeira vista, parece que o sindicato de Nova York, a Federação Unida de Professores (UFT), tem feito um dos melhores trabalhos na defesa dos professores e das escolas públicas. Muitos dos piores ataques que os docentes têm sofrido em outros lugares puderam ser prevenidos pela influência do sindicato em Albany. As escolas Charter não se multiplicaram tão rapidamente quanto em outras localidades, como por exemplo, na Califórnia. Escolas fechadas, devido aos baixos pontos nos testes, não estão sendo leiloadas de acordo com a melhor oferta, como está ocorrendo em Los Angeles. Mas as aparências enganam, enquanto o UFT tem sido, sem dúvida, capaz de proteger muitos dos vestígios do antigo sistema, como divulga politicamente, isso tem sido obtido com a alienação de seus aliados naturais, isolando a burocracia e permitindo ao sindicato a todos mas desaparecendo das escolas, e seriamente corroer no nível distrital, onde os membros do sindicato podem se negar a participar das atividades mais elementares de apoio, como se reunir com diretores de escolas 
para tratar de queixas. Uma estimativa que ouvi, de um legalista e apoiador da atual liderança, coloca o número de escolas sem funcionamento da seção sindical em mais de um terço das escolas, mas provavelmente mais próximo de três quintos. Muitos professores estão tão amedrontados de participar de reuniões do sindicato ou mesmo reunir, reservadamente, com representantes do sindicato no ambiente da escola. O que eles podem consentir em fazer, quando pressionados, é colocar materiais do sindicato nos escaninhos dos colegas, mas somente fazem isso em segredo. Um jovem professor, em uma seletiva escola de ensino médio de Manhattan, escola tida como "progressista" e apoiada por pais de esquerda, obteve uma avaliação "insatisfatória" pelo diretor por "assediar" os colegas. Ele colocou uma nota nos escaninhos dos demais colegas, informando sobre um encontro para discutir as políticas de admissão da escola. A representante do sindicato na escola se recusou a ajudar, porque queria estar nas boas graças do diretor, e os membros do sindicato não estavam dispostos a se envolver, pois seu trabalho, como eles veem, é registrar queixas que eles tem certeza que ocorreram. A UFT obviamente carece da capacidade - e vontade - para defender as escolas e seus membros na base. Alguns militantes teorizam, que o sindicato está se transformando, talvez na intenção consciente, de um "modelo de serviço" para uma organização de filiados, que veste o manto do sindicato mas de fato é um fornecedor de serviços ao consumidor, como um seguro de automóvel de baixo custo.

Ademais, os dirigentes da UFT ainda não enfrentaram um desafio sério. Na última mudança de papel, a coroa foi passada para Michael Mulgrew, que realmente ensinou nas escolas municipais, diferentemente de Randi Weingarten, um advogado que atuou como presidente da UFT e atualmente é presidente nacional da AFT. O rosto de Mulgrew é novo, mas o aparato continua impenetravelmente burocrático, e as políticas do sindicato são essencialmente como eram sob a gestão de Shanker. Há pouco sentido na forma como a direção sindical se apresenta ou atua, pois o sindicalismo docente tem sofrido um ataque que desafia a sua própria existência. A cobertura das lutas escolares pelo jornal do sindicato - ou a falta - mostra quão pequeno é o compromisso da UFT na proteção dos contratos, escolas e professores, assim como quão distante está das lutas por justiça social que os grupos com base em comunidades realizam. No jornal de 27 de outubro de 2001, a foto de Michael Mulgrew apareceu 9 vezes nas primeiras 11 páginas. Um artigo aplaudiu o sucesso da Junior ROTC em uma das escolas de ensino médio mais segregadas racialmente dentre as escolas da cidade. Nenhuma menção foi feita às campanhas anti-militarização que ocorrem em muitos pontos do país, por exemplo, em Los Angeles, com apoio do UTLA. Outra notícia informava aos professores sobre seus direitos - no contato com estudantes "problema", indiciplinados. Nenhuma menção em defesa ao trabalho de grupos sobre discriminação racial nas políticas disciplinares das escolas, ao trabalho de militantes para alterar a organização e cultura escolar em que estudantes "indisciplinados" são considerados menos importantes. Histórias sobre organização de escolas charter pintadas como algo brilhante - outra vitória! Havia uma pequena nota sobre o fato de que Occupy Wall Street estava a poucos blocos da sede do sindicato, uma história (com a foto de Michael Mulgrew) descrevia a participação 
do sindicato na coalisão que reivindica a não redução de impostos para milionários. Mas, a maior parte do jornal continha pequenos instantâneos sentimentais sobre trabalho de caridade desenvolvido por professores. Em função das condições reais do sistema escolar, incluindo os milhares de professores que são pagos (por ora), mas desempregados, cortes draconianos no financiamento sentidos na redução de recursos para suprimentos, tamanho das turmas que frequentemente excedem as normas contratuais (não obrigatórias), e a ausência de representantes sindicais em, no mínimo, um terço das escolas, faz do conteúdo dos jornais algo quase surreal. Certamente, esta é uma liderança sindical que não compreende que a publicidade de professores, que apoiam a importância da luta contra o câncer de mama, não será suficiente para defender as suas escolas, seus empregos, ou seus direitos de um sindicato que realmente os represente.

Uma das vitórias do UFT recente foi a organização dos trabalhadores de creches familiares, tornando-os sindicalizados. O UFT, em aliança com ACORN, utilizou sua força política para obter o direito de os trabalhadores de creches domésticas terem representação sindical e seu desconto nos salários, os quais são pagos pelo estado. Ocorreu uma eleição para representante de negociação, uma pequena fração de trabalhadores votaram, e o UFT venceu a escolha. Muito embora pareça ser um positivo, fortalecendo o sindicato e dando uma representação sindical aos trabalhadores explorados, de fato, o processo de cima-para-baixo falha em construir uma resiliência dos membros do sindicato que precisam vencer ou defender ganhos. Muitas vezes o que ocorre neste tipo de organização é que rapidamente, após a eleição para representantes, os novos membros são esquecidos. Nesse cenário familiar, que não é restrito à UFT, dirigentes usam os novos membros para fortalecer seus aparatos burocráticos no sindicato. A sindicalização dá aos trabalhadores acesso a algumas proteções muito necessárias e que mereciam ser garantidas; mas especialmente, quando membros não são parte do que constitui a base constituinte (professores no caso do UFT), eles ficam presos em um sindicato que faz muito pouco para a representar. $O$ caso dos trabalhadores de creches é particularmente mordaz porque a aliança UFT/ ACORN forçou o que tem sido uma organização autêntica baseada em comunidade de trabalhadores das creches, pelo grupo do Brooklyn, Families United for Racial and Economic Equality, a ser subsumida, de alguma forma, no sindicato.

Uma luz que se vislumbra no horizonte político do sindicato docente, da cidade de Nova York, é o Teachers Unite, que está tentando juntar ativistas e militantes pela justiça social na escolarização com docentes que querem ver o UFT modificado. Teachers Unite é pequeno mas crescente. Uma de suas atividades mais bem sucedidas tem sido realizar oficinas sobre a construção do sindicato nas escolas, ministradas por professores que são representantes do sindicato nas escolas. Essas atividades objetivam demonstrar o que poderia ser feito para construir o sindicato se a burocracia do UFT realmente quisesse fazer isso. Professores de outros grupos militantes, incluindo Grassroots Education Movement (GEM - Movimento de Educação de Base), que produziu um esplêndido vídeo que combate a desinformação, contida no filme Waiting for 
Superman, estão colaborando com Teachers Unite, em campanhas sobre justiça social nas escolas da cidade, inclusive com ajuda para organizar lutas contra o fechamento de escolas . Outro aspecto esperançoso é que Teachers Unite é parte de uma rede nacional, ainda emergente, de grupos pela reforma dos sindicatos.

\section{Occupy os Sindicatos!}

Se os sindicatos de professores devem continuar a existir como uma forma significativa de representação dos trabalhadores, os seus filiados precisam transformá-los - e rápido. O futuro do movimento depende dos militantes perceberem que eles, não os burocratas ou os dirigentes, tanto em âmbito estadual quanto nacional, devem ser os catalisadores da mudança. Assim como, não há de se escapardaconstruçãodo sindicato pela base, nãohácomocontornaroárduotrabalho de construir alianças autênticas, com pais e ativistas comunitários, coalizões que reconhecem desigualdades históricas e apoiam comunidades em suas demandas, em vez de de organizações de papel que são descartadas quando os sindicatos querem mostrar o apoio da comunidade. Dirigentes eleitos em diferentes níveis, desde membros de conselhos escolares a governadores, têm violado os contratos de sindicatos com impunidade. Ações judiciais, por si é o método preferido de negociação de muitos dirigentes com os não cumpridores de leis, não pode parar isso. O que pode é a ação direta, empreendida com pais e comunidade, como o CTU tem feito na luta contra o fechamento de escolas em Chicago.

Em contraste, a liderança nacional da AFT e NEA perseguem a estratégia de aproximação com seus "amigos" do Partido Democrata, incluindo o Presidente Obama. Isso enfraquece as bravas atividades de muitos docentes lutando em suas escolas contra as políticas que Obama e Duncan estão promovendo. Por exemplo, ambos os sindicatos nacionais têm aceitado o uso dos testes padronizados para avaliar o desempenho dos estudantes e pagamento dos professores, a fim de, dizem, ficarem "acreditados". Mas "acreditados" para quem? Certamente, não para docentes que arriscam seus meios de sobrevivência por se posicionarem contra os danos causados à educação pela redução ao ensino de/para o teste. $O$ representante da AFT, na sua escola charter, compartilhou comigo sua indignação e consternação com o que ocorreu quando ele chamou o sindicato estadual para ajudar na negociação com a demanda do diretor para aumentos salariais vinculados aos resultados dos estudantes nos testes. A elefoi dito que as mudanças demandadas pelo diretor eram parte da política oficial do AFT.

Em julho de 2011, a NEA oficialmente endossou Obama para Presidente. A AFT sem dúvida seguirá o exemplo, uma vez que o trabalhismo organizado tem que decidir, o tempo é crucial para uma tomada de decisão. Embora a AFT e a NEA nacionalmente estejam no bolso dos Democratas, um cenário diferente pode ocorrer nas eleições de conselhos escolares locais. Sindicatos de professores estão começando a concorrer para os conselhos escolares. Muitas vezes, os sindicatos apoiam candidatos com a mesma racionalidade do "mal menor" que os sindicatos estaduais e nacionais usam para endossar os Democratas. Contudo, em algumas localidades essa estratégia está sendo desafiada. Em vez de eleger alguém, 
qualquer um, que esteja em posição social melhor, os sindicatos de professores estão pensando em como podem usar as eleições como uma oportunidade para construir umapoio desde a base. Campanhas para as eleições de conselhos escolares podem estar testando bases para construir novas alianças eleitorais, alianças que estão independentes dos dois principais partidos, que falam verdades sobre o poder das corporações e avançam na visão de uma educação pública que apoia a colaboração dentre os que constroem a escolarização. Assim como Occupy Wall Street demonstrou, o país está faminto por líderes que falem contra os excessos do capitalismo. Nem a NEA ou a AFT podem prover tal liderança, tampouco ser parceiros em um movimento que desafie Wall Street, tanto quanto seus dirigentes de cúpula querem que os sindicatos sejam incluídos como colaboradores na manutenção da dominação capitalista da sociedade norte-americana e do globo.

Como pesquisadores do trabalho, Mayssoun Sukarieh e Stuart Tannock explicam, embora a AFT apoie suas extensas e distantes operações globais com "retórica de mente elevada da solidariedade global do trabalho, boa vontade filantrópica e promoção da democracia," o sindicato quer, acima de tudo, expandir a hegemonia norte-americana. As operações internacionais da AFT são vastas, variando desde a "Bolívia a Burma e Quênia ao Cazaquistão" [14]. Ironicamente, a AFT pretende educar sindicalistas docentes ao redor do mundo para abandonar as tradições do sindicalismo de movimento social que deveríamos estar aprendendo - e imitando nos Estados Unidos. Dada as reivindicações de alguns progressistas de que a AFT mudou, após o fim da Guerra Fria e a morte de Shanker, é importante notar que Sukarieh e Tannock afirmam que a AFT continua com seu legado da guerra fria, amplamente não interrompido. Seu atual diretor de assuntos internacionais, David Dorn, foi também diretor durante a era Shanker. Ao invés de questionar, desculpar-se, ou distanciar-se de todo o seu trabalho internacional passado, a AFT celebra e explicitamente reivindica a continuidade da mesma linha de atividade... A AFT continua a expandir seus programas internacionais... a partir de sua base na Europa Oriental, nos 1990, ao foco atual no Oriente Médio. (p. 186).

AFT e NEA se apoiam no seu tamanho, riqueza e vínculos com o governos dos EUA para dominarem a política da Internacional da Educação (El), a federação global dos sindicatos de professores. Costumavam existir diferenças significativas entre a NEA e a AFT quanto à política internacional, sendo a NEA mais liberal. Contudo, aquelas distinções, mesmo efêmeras, parecem ter sido perdidas. Ambas se juntaram para esmagar a democracia na conferência da El em Capetown, no último verão, na qual usaram o seu controle sobre o aparato administrativo da El para forçar uma palatável (para elas) resolução sobre a Palestina e Israel. De acordo com um participante da conferência, com quem conversei, AFT e NEA chocaram os delegados da Europa Ocidental com o seu descarado (e bem sucedido) esforço para controlar o debate e forçar uma solução mais de acordo com a política externa norte-americana.

Três diferentes resoluções sobre a Palestina e Israel foram apresentadas à conferência. Uma veio da direção da El, outra do sindicato do Ensino Superior do 
Reino Unido, Sindicato das Universidades e Faculdades, e a terceira do Sindicato Nacional de Professores (National Union of Teachers - NUT). Operando muito mais como a direção da AFT faz em suas próprias convençoes, a AFT e a NEA manobraram para suprimir a resolução do NUT, a qual era uma condenação direta das ações de Israel em relação à Palestina. Primeiro, tentaram persuadir a presidência do NUT para retirar a resolução. Esse esforço de intimidação falhou, então eles advertiram os delegados do NUT, que se eles persistissem em apresentar a resolução, a delegação da AFT abandonaria a conferência. Um funcionário da NEA foi preparado para negociar no escritório administrativo da El em nome da AFT e da NEA, e por fim, uma resolução de "compromisso" foi aprovada, sem qualquer crítica mais aguda à política de Israel. Delegados do Oriente Médio ficaram enfurecidos com a resolução e por terem sido silenciados no debate.

Com todas as lutas políticas em andamento no mundo, com ataques orquestrados contra os sindicatos de professores, por que a AFT e a NEA fizeram da resolução do NUT sobre a Palestina o foco principal de suas intervenções políticas na conferência da El? Por que a direção da NEA e da AFT comprometeria sua legitimidade política para ostentar seu controle sobre o aparelho administrativo da EI? A resposta está na natureza desequilibrada da bússola política da AFT e da NEA, permanentemente apontada para a direção dos desejos do governo dos EUA. Nada conta tanto para as direções dessas entidades quanto às prerrogativas do capitalismo norte-americano e do governo que protege isso. Sua lealdade com o imperialismo dos EUA está presente em quase todas as decisões políticas. Por exemplo, a NEA e a AFT proíbem a filiação de sindicatos cubanos e chineses na El porque não são livres do controle governamental. É razoável, mas por que permitem a participação do sindicato egípcio - inteiramente controlado pela ditadura de Mubarak - até que o sindicato ficasse inadimplente com suas taxas muito pouco antes Mubarak ser derrubado? Líderes de sindicatos docentes do sul global objetaram a contradição entre o apoio professado pela El para os sindicatos com livre negociação ao redor do mundo e a sua, isto é, da NEA e da AFT, aplicação de critério de mão única que coincide com os desejos do governo dos EUA. Sob a pressão de vida e morte de seus próprios governos e temerosos de futuros ataques das agências internacionais que respondem a Washington, sindicalistas docentes da Ásia e África ficaram compreensivelmente relutantes em desafiar a AFT e a NEA. Dado este desequilíbrio de poder entre sindicatos no sul global e a AFT e a NEA, os sindicatos da Europa Ocidental têm a responsabilidade especial de lutar pela democracia na El e pela consistente aplicação das regras de medidas se os sindicatos são sem dúvida "livres" do controle governamental.

Quando Naomi Klein falou no Occupy Wall Street, observou que o restante do mundo tinha ficado esperando por este desafio no coração do capitalismo. O mesmo é verdadeiro para o renascimento do sindicalismo docente nos EUA. Professores e estudantes, em todo o globo, precisam de professores em seus países para ocupar seus sindicatos. Até o momento deste escrito, os olhos do mundo estão sobre os corajosos ativistas que enfrentam a elite mais poderosa do mundo no centro de Manhattan. Nossos olhos também deveriam estar sobre a 
heroica atividade de professores movimentando-se para ocupar seus sindicatos. $\mathrm{O}$ futuro da educação pública globalmente depende, em boa medida, deles.

* Professora no Departamento de Educação Elementar e Secundária. Ministra cursos de Fundamentos Sociais da Educação e de Currículo e Ensino na New Jersey City University. É membro do corpo editorial de New Politics. É co-editora, com Mary Compton do livro The Global Assault on Teaching, Teachers, and Their Unions: Stories for Resistance, e autora de um novo livro sobre para militantes de sindicatos docentes.

O texto foi originalmente publicado, sob o título Teacher Unionism Reborn, em New Politics, Vol. XIII, n. 4, Whole Number 52, 2012. <http://newpol.org/content/teacher-unionism-reborn>

Traduzido por Álvaro Moreira Hypolito - Universidade Federal de Pelotas (UFPel).

\section{Correspondência}

Lois Weiner - Department of Elementary and Secondary Education, Professional Studies Building 329,

New Jersey City University, 2039 Kennedy Boulevard, Jersey City, New Jersey 07305-1597.

E-mail: drweinerlo@gmail.com ou lweiner@njcu.edu

Recebido em 22 de abril de 2013

Aprovado em 27 de julho de 2013 